\title{
Research on hydrodynamic properties of annular cavitator with water injection
}

\author{
Zhenyu Jiang, Associate Research Fellow, \\ Min Xiang, Lecturer, \\ Mingdong Lin, Ph.D., \\ Weihua Zhang, Professor, \\ Shuai Zhang, M.Sc., \\ National University of Defense Technology Changsha, P.R. CHINA
}

\begin{abstract}
Annular cavitator with water injection is one of the key parts of the long-range supercavitating vehicle powered by water ramjet. In this paper, hydrodynamic properties of annular cavitator are studied numerically. The standard $k \sim \varepsilon$ turbulence model is coupled with the Reynolds Averaged Navier-Stokes (RANS) equations to model the natural supercavitation process. The multiphase flow is considered as a mixture of varying density and modeled by the mass exchange equations. To fully understand this process, numerical simulations were performed for different annular cavitators. Computational Fluid Dynamics (CFD) results, including the pressure distribution and forces acting on the cavitator surface, mass flow and pressure loss of water injection, various supercavity sizes, were obtained and analyzed. The pressure distribution on the cavitator surface was significantly changed which resulted in $4 \sim 6 \%$ increase of the total drag of the vehicle. The results show that the mass flow and velocity of the injection water is mainly dependent on the tube size, while the total pressure loss of the water injection is mostly related to the outlet pressure. Supercavity generated by annular cavitator is smaller than that of the discal one. Based on the correlation analysis of the supercavity size and other factors, it could be concluded that the contraction of the cavity size is mainly caused by the diffluent mass flow of the water injection.
\end{abstract}

Key words: supercavitation; computation fluid dynamics (CFD); annular cavitator; water injection

\section{INTRODUCTION}

Cavitation, which happens when a vehicle travels fast enough underwater, brings extra noise, surface erosion, and other problems. To avoid cavitation, traditional underwater vehicles could hardly travel faster than $70 \mathrm{kn}$. Supercavitation, in contrast, which could reduce the drag by more than $90 \%$, has been proved to be a revolutionary way to achieve ultrahigh speed underwater [1]. Due to the successful applications of the Russian torpedo 'Shkval' and the US supercavitating projectile 'RAMICS', supercavitating vehicles have received increasing research interests in recent years [2-4].

With stunt shape and sharp edge, cavitator generates and sustains a supercavity to envelope the whole vehicle during high speed motion. Both theoretical and numerical studies have been carried out to enhance the understanding of various properties of cavitators and the supercavitating flow.

By applying the theorem of the independence of cavity section expansion proposed by Logvinovich $[5,6]$, pioneering studies have been conducted by Russian and Ukrainian researchers such that they have been widely used for the predicting of the cavity shape $[7,8]$. L.Sedov studied the jet cavitator which ejects water stream into the flow. In this case the body will suffer only half drag when the cavitation number is near zero [9]. Using computationally supercavitating flow,
Owis et al considered the compressibility of supercavitating flow and improved a numerical method for both single and multi-phase flows [10-12]. Drag force for NACA66 foil and a flat plate was investigated by Seif and the CFD model was successfully tested [13]. Carried out by Kuklinski, experimental studies of hydrodynamic properties of different cavitators provided test data for the dynamic modeling of cavitators [14]. Studied by Ahn, Shafaghat, and Lin, optimal designs of conical or spherical cavitators proved that a proper shape could improve performance of the cavitator [15-17]. To achieve long-range supercavitating motion, the water ramjet is the best propulsion device for supercavitating vehicles. In this case, water injection from the cavitator is required, which makes conducting research on annular cavitators necessary.

In this paper hydrodynamic properties of the annular cavitator are studied in detail. Based on the Reynolds Averaged Navier-Stokes (RANS) equations which is coupled with the standard $\mathrm{k} \sim \varepsilon$ turbulence model, the supercavitating flow is considered as a varying-density single-phase flow. The water injection processes with assumed different tube size and outlet pressures are studied. Based on the simulation of different water injection conditions, total drag of the annular cavitators are obtained. The mass flow and the pressure loss of the water injection are studied. Related factors which affect the supercavity size are investigated by using the correlation 
analysis. Experimental results shown in this paper can be utilized for the designing of supercavitating vehicles propelled by water ramjet.

\section{MODELING AND COMPUTATIONAL APPROACHES}

\section{Governing equations}

Based on three dimensional Reynolds Averaged NavierStokes equations, the supercavitating flow consisted of water and vapour is considered as a single phase of the same pressure and velocity field and is modelled by the mass exchange equations. The steady supercavitation flow is considered isothermal, therefore the energy equation is not considered.

The continuity and momentum equations of the mixture phase are given below:

$$
\begin{gathered}
\frac{\partial\left(\rho_{\mathrm{m}}\right)}{\partial \mathrm{t}}+\nabla \mathrm{g}\left(\rho_{\mathrm{m}} \mathbf{u}\right)=0 \\
\frac{\partial\left(\rho_{\mathrm{m}} \mathbf{u}\right)}{\partial \mathrm{t}}+\nabla \mathrm{g}\left(\rho_{\mathrm{m}} \mathbf{u} \times \mathbf{u}^{\mathrm{T}}\right)= \\
=-\nabla \mathrm{p}+\nabla \mathrm{g}\left[\mu_{\mathrm{m}}\left(\nabla \mathbf{u}+\nabla \mathbf{u}^{\mathrm{T}}\right)\right]+\rho_{\mathrm{m}} \mathbf{g}
\end{gathered}
$$

The continuity equation of the vapour phase is shown as follows:

$$
\frac{\partial\left(\rho_{\mathrm{v}} \alpha_{\mathrm{v}}\right)}{\partial \mathrm{t}}+\nabla \mathrm{g}\left(\rho_{\mathrm{v}} \alpha_{\mathrm{v}} \mathbf{u}\right)=\dot{\mathrm{m}}^{+}-\dot{\mathrm{m}}^{-}
$$

where $\mathbf{u}$ is the velocity vector of the mixture, $g$ is the gravity vector, $\rho, \alpha$ and $\mu$ represent density, volume fraction, and viscosity, respectively, subscript $1, \mathrm{v}$ and $\mathrm{m}$ represent liquid phase, vapour phase, and mixture phase separately, $\dot{\mathrm{m}}^{+}, \dot{\mathrm{m}}^{-}$are the source terms caused by vaporization and condensation.

The mixture property, $\phi_{\mathrm{m}}$, can be obtained by:

$$
\phi_{\mathrm{m}}=\phi_{1} \alpha_{1}+\phi_{\mathrm{v}} \alpha_{\mathrm{v}}
$$

where $\phi$ stands for density, viscosity, and so on

At last, volume fraction-conservation equation is as follows:

$$
\alpha_{1}+\alpha_{\mathrm{v}}=1
$$

\section{Natural cavitation model}

The Rayleigh-Plesset equation which provides the basis for the rate equation controlling vaporization and condensation, is given as follows:

$$
\mathrm{R}_{\mathrm{B}} \frac{\mathrm{d}^{2} \mathrm{R}_{\mathrm{B}}}{\mathrm{dt}^{2}}+\frac{3}{2}\left(\frac{\mathrm{dR} \mathrm{R}_{\mathrm{B}}}{\mathrm{dt}}\right)^{2}=\frac{\mathrm{p}_{\mathrm{v}}-\mathrm{p}}{\rho_{\mathrm{l}}}-\frac{2 \sigma}{\rho_{\mathrm{v}} \mathrm{R}_{\mathrm{B}}}
$$

where:

$R_{B}-$ represents the gas bubble radius,

$\mathrm{p}_{\mathrm{v}} \quad$ - saturated vapour pressure

$\mathrm{p}-\mathrm{t}$ the pressure in the liquid surrounding the bubble,

$\mathrm{p}_{1} \quad-$ the liquid density,

$\sigma \quad-$ the coefficient of surface tension between the liquid and vapour.

By disregarding the second-order terms and surface tension, the rate of vaporization and condensation are shown below:

$$
\dot{\mathrm{m}}^{+}=\mathrm{C}_{\mathrm{e}} \frac{3 \alpha_{\text {nuc }} \alpha_{1} \rho_{\mathrm{v}}}{\mathrm{R}_{\mathrm{B}}} \sqrt{\frac{2}{3} \frac{\mathrm{p}_{\mathrm{v}}-\mathrm{p}}{\rho_{\mathrm{l}}}}, \quad \mathrm{p}<\mathrm{p}_{\mathrm{v}}
$$

$$
\dot{\mathrm{m}}^{-}=\mathrm{C}_{\mathrm{c}} \frac{3 \alpha_{\mathrm{v}} \rho_{\mathrm{v}}}{\mathrm{R}_{\mathrm{B}}} \sqrt{\frac{2}{3} \frac{\mathrm{p}-\mathrm{p}_{\mathrm{v}}}{\rho_{\mathrm{l}}}}, \quad \mathrm{p}>\mathrm{p}_{\mathrm{v}}
$$

where:

$\alpha_{\text {nuc }} \quad-$ the volume fraction of the nucleation sites,

$\mathrm{C}_{\mathrm{e}}, \mathrm{C}_{\mathrm{c}}-$ empirical factors which may be different for the rate of vaporization and condensation; usually: $C_{e}=50$, $\mathrm{C}_{\mathrm{c}}=0.01$.

\section{Turbulence model}

The standard $\mathrm{k} \sim \varepsilon$ turbulence model is used in this study. The turbulence kinetic energy, $\mathrm{k}$, and its dissipation rate, $\varepsilon$, are obtained from the following transport equations:

$$
\begin{gathered}
\frac{\partial}{\partial \mathrm{t}}\left(\rho_{\mathrm{m}} \mathrm{k}\right)+\nabla \mathrm{g}\left(\rho_{\mathrm{m}} \mathrm{vk}\right)=\nabla \mathrm{g}\left[\left(\mu+\frac{\mu_{\mathrm{t}}}{\sigma_{\mathrm{k}}}\right) \nabla \mathrm{k}\right]+\mathrm{G}_{\mathrm{k}}-\rho_{\mathrm{m}} \varepsilon \\
\frac{\partial}{\partial \mathrm{t}}\left(\rho_{\mathrm{m}} \mathrm{k}\right)+\nabla \mathrm{g}\left(\rho_{\mathrm{m}} \mathrm{v} \varepsilon\right)= \\
=\nabla \mathrm{g}\left[\left(\mu+\frac{\mu_{\mathrm{t}}}{\sigma_{\varepsilon}}\right) \nabla \varepsilon\right]+\frac{\varepsilon}{\mathrm{k}}\left(\mathrm{C}_{1 \varepsilon} \mathrm{G}_{\mathrm{k}}-\mathrm{C}_{2 \varepsilon} \rho_{\mathrm{m}} \varepsilon\right)
\end{gathered}
$$

where:

$\mu_{\mathrm{t}}=\rho \mathrm{C}_{\mu} \mathrm{k}^{2} / \varepsilon-$ the viscosity of turbulence,

$\mathrm{G}_{\mathrm{k}}=2 \mu_{\mathrm{t}} \nabla \mathrm{v}-$ the kinetic energy of turbulence,

$\sigma_{\mathrm{k}}, \sigma_{\varepsilon} \quad-$ the Prandtl number of $\mathrm{k}$ and $\varepsilon$, respectively. Again, $\sigma_{1 \varepsilon}=1.44, \sigma_{2 \varepsilon}=1.92, \mathrm{C}_{\mu}=0.09$, $\sigma_{\mathrm{k}}=1.0, \sigma_{\varepsilon}=1.3$.

\section{Settings for simulation}

The vehicle model is illustrated in Fig. 1. The length of the vehicle is $2 \mathrm{~m}$, while the diameter of the body is $0.2 \mathrm{~m}$. The set diameter of the cavitator is $10 \mathrm{~cm}$. To avoid the unstable region of the injection hole on the cavitator, the length of the tube is set to $1 \mathrm{~m}$. The bottom of the tube is assumed to be the outlet surface. The incoming flow velocity is $100 \mathrm{~m} / \mathrm{s}$ and the environmental pressure is $0.2 \mathrm{MPa}$.

The generic CFX code was used to investigate the liquid flow around the supercavity. Numerical calculations were performed over a $180^{\circ}$ radial sector of the field with symmetrical boundary conditions. The computational mesh corresponding to the schematic geometry is shown in Fig. 2. In summary, over 500,000 hexahedral elements were formed and non-uniformly distributed within the entire computational domain. The transport equations were discretized by the finite volume approach. The convection terms were approximated by a high-order resolution scheme while the diffusion terms - by the second-order central difference scheme. Convergence was achieved within 2500 iterations when the RMS (root mean square) residual dropped below 10-6.

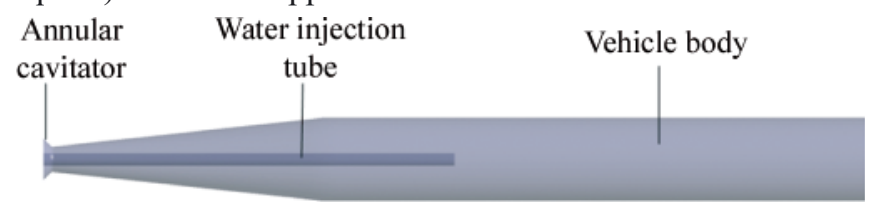

Fig. 1. Schematic geometry of vehicle model

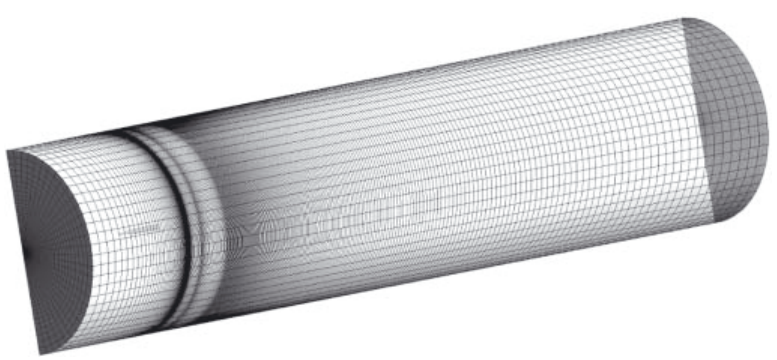

Fig. 2. Computational mesh of the annular cavitator 
To consider the effect of the outflow pressure and tube diameter, different simulation cases were performed accordingly (Tab. 1). The same condition is assumed for case 3 and 7. The disk cavitator with the same diameter is selected to be the case 0 for comparison purpose.

Tab. 1. Values of tube diameter and outlet pressure for different CFD cases

\begin{tabular}{|c|c|c|c|c|c|}
\hline Case & $\begin{array}{c}\mathbf{P}_{\text {out }} \\
{[\mathbf{M P a}]}\end{array}$ & $\begin{array}{c}\mathbf{D}_{\text {tube }} \\
{[\mathbf{c m}]}\end{array}$ & Case & $\begin{array}{c}\mathbf{P}_{\text {out }} \\
{[\mathbf{M P a}]}\end{array}$ & $\begin{array}{c}\mathbf{D}_{\text {tube }} \\
{[\mathbf{c m}]}\end{array}$ \\
\hline 1 & 4.0 & $\mathbf{2 . 0}$ & 5 & $\mathbf{3 . 0}$ & 4.0 \\
\hline 2 & 4.0 & $\mathbf{3 . 0}$ & 6 & $\mathbf{3 . 5}$ & 4.0 \\
\hline 3 & 4.0 & $\mathbf{4 . 0}$ & 7 & $\mathbf{4 . 0}$ & 4.0 \\
\hline 4 & 4.0 & $\mathbf{5 . 0}$ & 8 & $\mathbf{4 . 5}$ & 4.0 \\
\hline
\end{tabular}

RESULTS AND DISCUSSION

\section{Pressure distributions and drag forces}

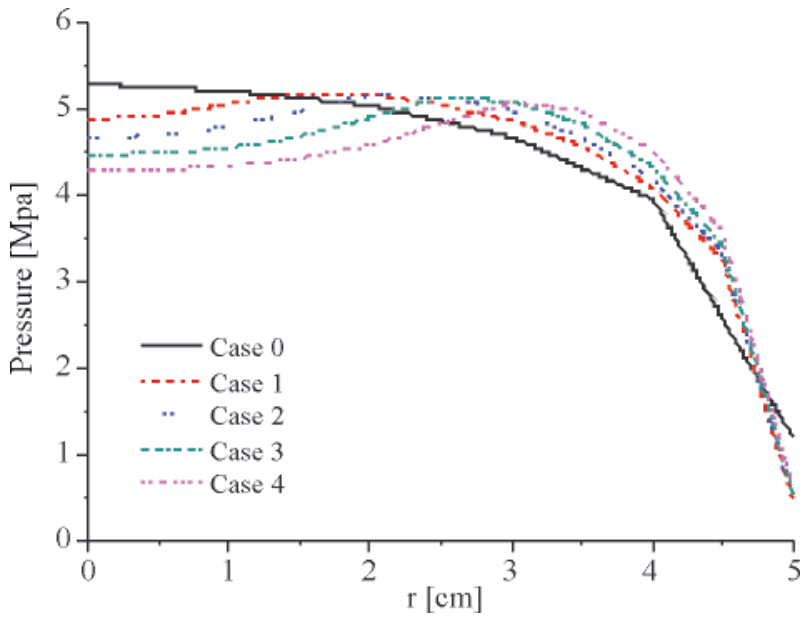

Fig. 3. Pressure distributions on the cavitator surface for case 1 through 4

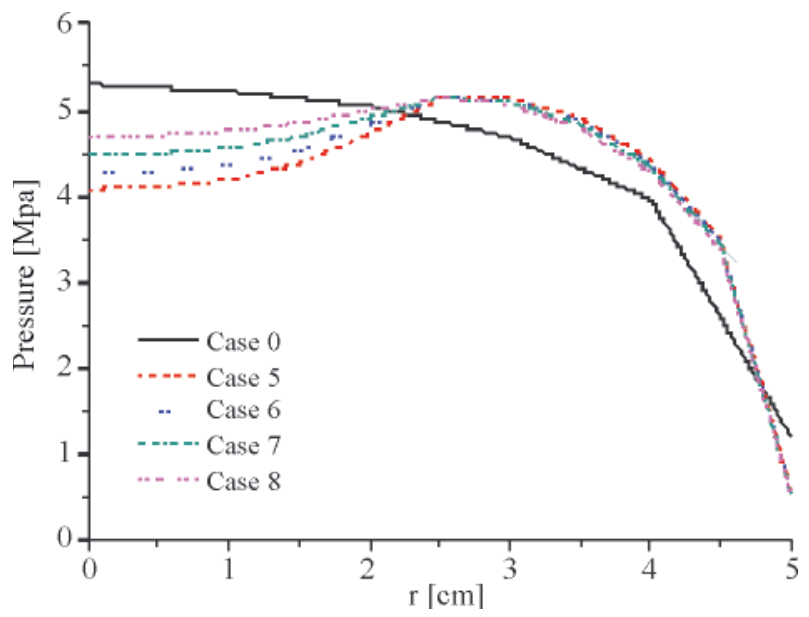

Fig. 4. Pressure distributions on the cavitator surface for case 5 through 8

Based on the assumption that the static pressure of the bottom of the tube to be $4 \mathrm{MPa}$, the pressure distributions on annular cavitators (case 1 through 4), are presented in Fig. 3. In the radial direction, the pressure increases on the tube section and then decreases on the cavitator. As the diameter of the injection tube increases, the stagnation ring of the cavitator surface moves outward along the radial direction. The pressure in the centre is larger than the outlet pressure, which means that certain pressure loss happened during the water injection. As shown in Fig. 4, although the outlet pressures are different, the position of the maximum pressure is almost the same. It means that position of stagnation ring is hardly related to the outlet pressure, which only depends on the size of the injection tube. Furthermore, the pressure distribution on the ring part of the cavitator surface is independent on the pressure distribution in the tube section.

Tab. 2. Forces acting on region of cavitator with different tube diameter

\begin{tabular}{|c|c|c|c|c|}
\hline Case & $\mathbf{F}_{\text {cav }}[\mathbf{N}]$ & $\mathbf{F}_{\text {tube }}[\mathbf{N}]$ & $\mathbf{F}_{\text {total }}[\mathbf{N}]$ & Increment $[\%]$ \\
\hline 0 & 30608 & 0 & 30608 & 0 \\
\hline 1 & 30260 & 1565.4 & 31825.4 & 3.98 \\
\hline 2 & 28720 & 3408 & 32128 & 4.97 \\
\hline 3 & 26480 & 5870 & 32350 & 5.69 \\
\hline 4 & 23480 & 8886 & 32366 & 5.74 \\
\hline 5 & 26740 & 5488 & 32228 & 5.29 \\
\hline 6 & 26640 & 5676 & 32316 & 5.58 \\
\hline 7 & 26480 & 5870 & 32350 & 5.69 \\
\hline 8 & 26260 & 6076 & 32336 & 5.65 \\
\hline
\end{tabular}

By integrating the pressure in the radial direction the forces acting on the cavitator surface are obtained (Tab. 2). As the tube diameter increases (case 1 through 4), the cavitator force decreases significantly due to contraction of the cavitator surface. Meanwhile, the forces acting on the tube section increase faster. As a result, the total forces acting on the vehicle increase by about $4 \sim 6 \%$. Furthermore, the larger the tube diameter the greater increase of the total force. Total forces in the case 5 through 8 are still larger than the ones in the case 0 , but they change slightly as the outlet pressure of the tube varies. Such variety means that the contribution of pressure in the central tube section results in a relatively small contribution to the total force. Outlet pressure of the tube shows a lower significance to the total force acting onto the supercavitating body.

\section{Mass flow and pressure loss}

The water injection mass flows and velocities versus tube diameters are illustrated in Fig. 5. The results show that the mass flow is almost proportional to the tube section area and that the velocity of the injecting flow is less sensitive to the tube size. As shown in Fig. 6, both the mass flow and water injection velocity decrease as the outlet pressure of the tube increases. Compared with the results in Fig. 5, the mass flow is rather more dependent on the tube size than on the outlet pressure.

Due to the sudden contraction of the tube section and the friction on the tube wall, pressure loss is unavoidable during water injection. Since the water is incompressible and the tube diameter is constant along the pipe, the total pressure loss is equal to the static pressure decrease of the water. The pipe static pressure distribution is illustrated in Fig. 7. In all the cases significant pressure drop and turbulence can be observed near the inlet to the pipe. It means that the pressure distribution near the inlet is highly unstable. In case 1, for the smallest tube diameter, pressure loss along the pipe is the fastest in comparison with the ones for other tube diameters, while case 4 shows the opposite result. Total pressure loss is larger when the injection tube diameter is relatively smaller. In case 1 , the total loss is about $1 \mathrm{MPa}$. Regarding the cases 5 through 8 , it can be concluded that the pressure loss is proportional to the pressure difference between the total pressure of flow field and the outlet pressure. The smaller outlet pressure the larger pressure loss. In case 5, the total pressure loss achieves $1.38 \mathrm{MPa}$ while in case 8 the loss amounts only to $0.34 \mathrm{MPa}$. In summary, by applying larger tube size and higher outlet pressure, the total pressure loss could be reduced dramatically. 


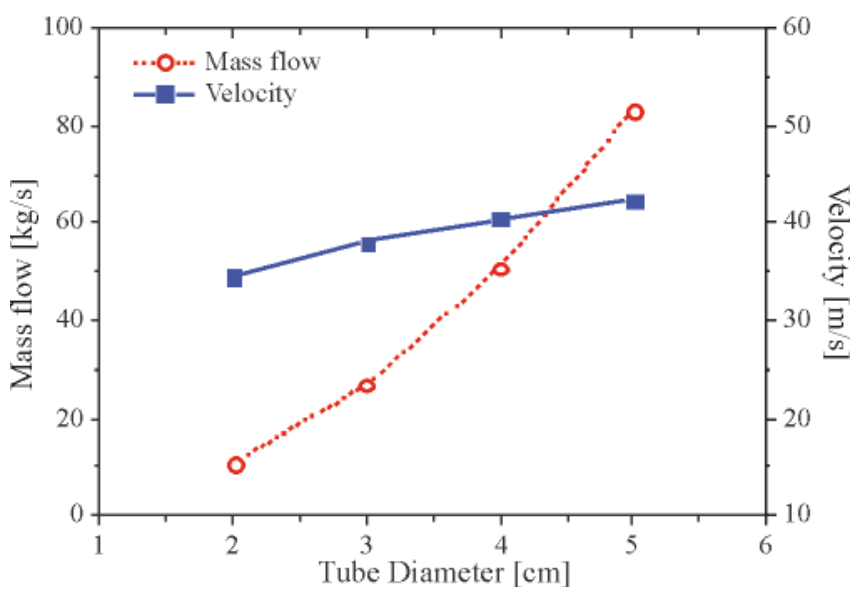

Fig. 5. Mass flow and velocity vs. tube diameter

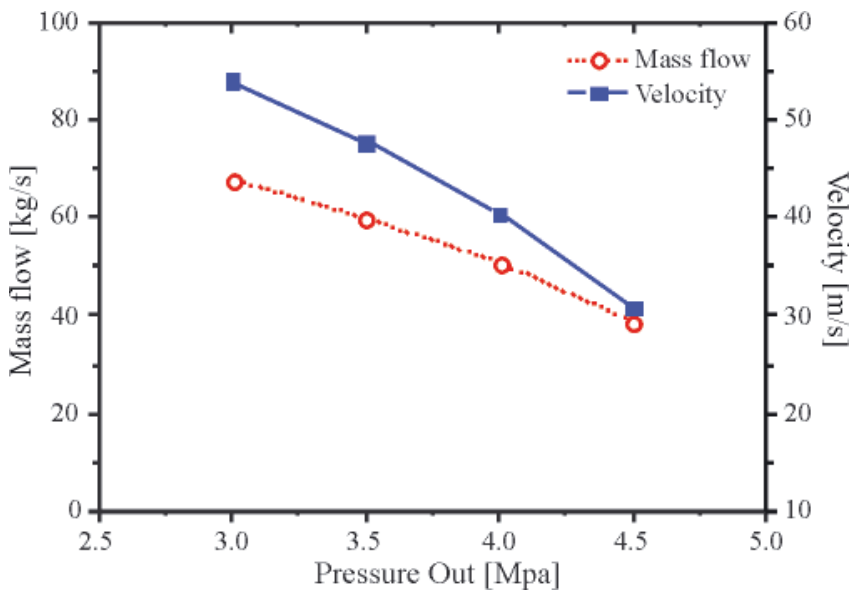

Fig. 6. Mass flow and velocity vs. outlet pressure

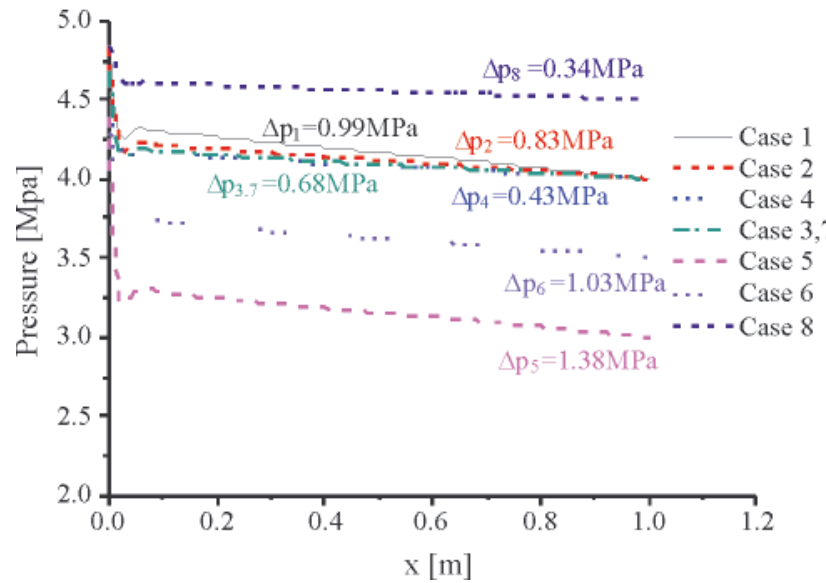

Fig. 7. Pressure loss of the water injection versus tube length

\section{Dimension of supercavities in different cases}

According to the CFD algorithm the multi-phase supercavitating flow is treated as a mixture of varying density. Thus the supercavity boundary is considered as the position where the density of flow is $\rho_{\mathrm{m}}=0.5$. The supercavities generated by different cavitators are presented in Fig. 8. Clear reentrant jet flow can be observed in the tail of supercavities. Despite the total force increase on cavitator surface, supercavities generated by the annular cavitator are smaller than those generated by the disc in case 0 . We can conclude that the cavity size is dependent not only on the drag force. When passing from case 1 to case 4 , as the tube diameter increases, the cavity size becomes smaller. However, when passing from case 5 to case 8 , the cavity size grows due to the outlet pressure increase.
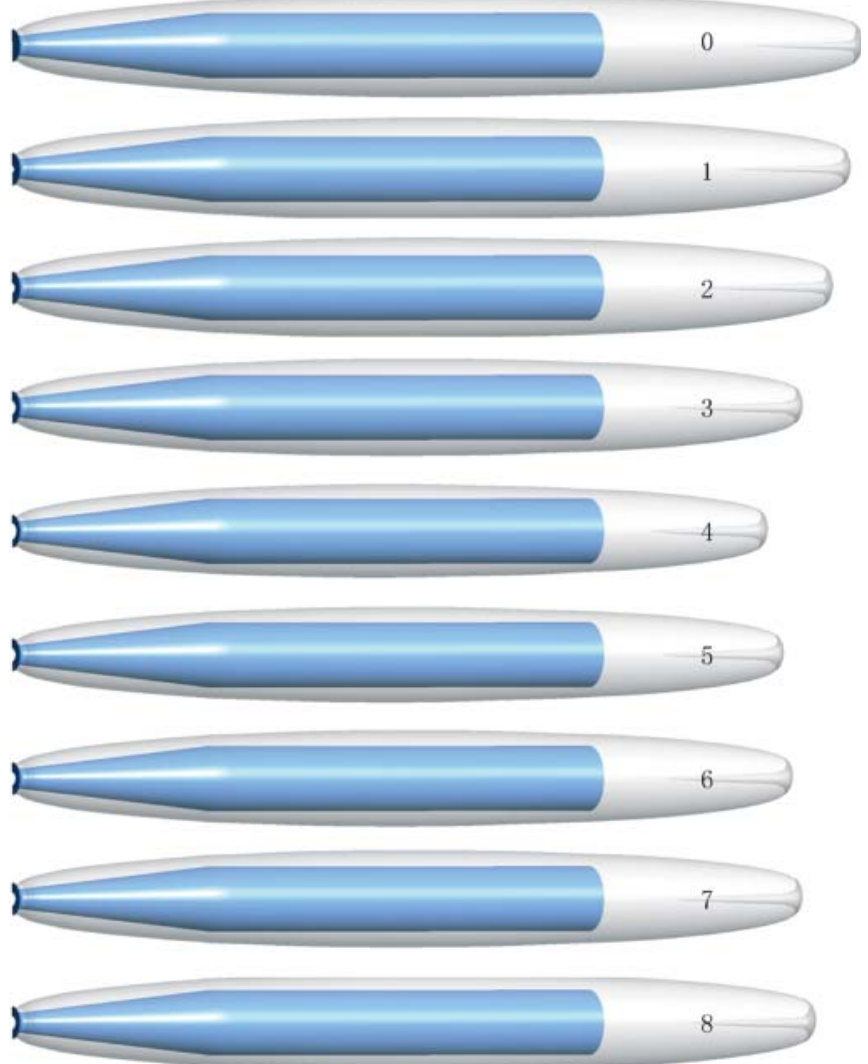

Fig. 8. Supercavities generated by different cavitators

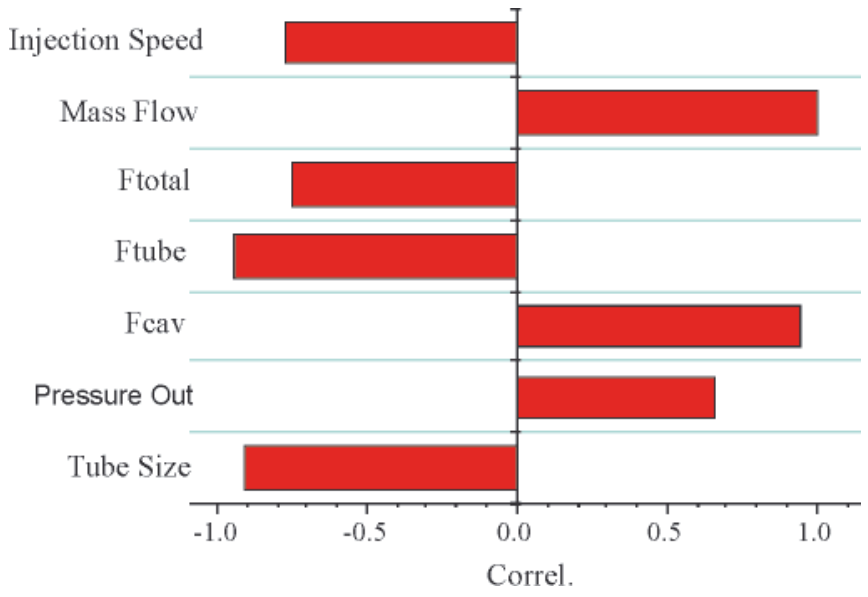

Fig. 9. Coefficients of correlation between cavity size and other possible factors

To underlie the reason of cavity contraction, a correlation analysis was performed. The correlation coefficients between cavity size and other possible factors are presented in Fig. 9. The result shows that the cavity size is positively correlated with the cavitator force and mass flow through the tube. The force acting on tube section and the tube size is correlated negatively. The correlation coefficient between the cavity size and water injection mass flow is equal to 0.999 , which indicates that the supercavity contraction is caused by the water injection diffluence in the flow field.

\section{CONCLUSIONS}

In this paper a numerical research on the natural supercavitation problem is performed with the use of a highspeed annular cavitator. To model the supercavitating flow, the liquid and vapour phase of the flow field is considered as 
a mixture of varying density. The RANS equations coupled with the standard $\mathrm{k} \sim \varepsilon$ turbulence model are applied to CFD simulation. Properties of the flow field are obtained for given different injection tube size and outlet pressure conditions.

Pressure distributions, forces acting on the cavitator surface and injection water flow properties are analyzed. The obtained results show that the stagnation region on annular cavitator moves outward along the radial direction, which results in about $4 \sim 6 \%$ increase of the total drag. The tube diameter affects the drag increase more than the pipe outlet pressure. The injection water mass flow mainly depends on the tube diameter. Both the mass flow and injection velocity increase with the tube diameter and decrease with the outlet pressure. The design of the water injection system will affect not only the amount of injected water but also the total pressure loss. The pressure loss is inversely proportional to the tube diameter.

The annular cavitators form smaller supercavities than the discal one of the same diameter. According to the correlation analysis it is caused by diffluence of the water injection.

To better understand the performance of a water- ramjetpropelled supercavitating vehicle, it is essential to take it into account the drag increase and the cavity size contraction caused by the annular cavitator. In such case, motion dynamics of a supercavitating vehicle may need some modification. Furthermore, in terms of mass flow and pressure loss, the obtained results would be very helpful in optimal designing the water injection system.

\section{BIBLIOGRAPHY}

1. Savchenko Y.N.: Supercavitation-problems and perspectives. In: CAV2001.; 2002.

2. Ashley S.: Warp Drive Underwater. Scientific American Special Online Issue, 2002.

3. Stinebring D.R., Cook R.B., Dzielski J.E., Kunz R.F.: HighSpeed Supercavitating Vehicles. In: AIAA Guidance, Navigation, and Control Conference and Exhibit. Keystone, Colorado, USA; 2006.

4. Kam W.N.: Overview of the ONR Supercavitating High-Speed Bodies Program. In: AIAA Guidance, Navigation, and Control Conference and Exhibit. Keystone, Colorado, USA; 2006.

5. Garabedian P.R.: The principle of independence of the cavity section expansion(Logvinovich's principle) as the basis for investigation on cavitation flows. In: RTO/NATO Lecture Series 005 Supercavitating Flows. France; 2002.

6. Logvinovich G.V.: Hydrodynamics of flows with free boundaries: Halsted Press; 1973.

7. Savchenko Y.N.: Experimental investigation of supercavitating motion of bodies. In: RTO/NATO Lecture Series 005 Supercavitating Flows. France; 2002.
8. Semenenko V.N.: Artificial supercavitation. physics and calculation. In: RTO/NATO Lecture Series 005 Supercavitating Flows. France; 2002.

9. Sedov L.I.: Mechanics of Continuum. Moscow: Nauka Publishing House; 1976.

10.Owis F.M., Nayfeh A.H.: A compressible multi-phase flow solver for the computation of the supercavitation over high-speed torpedo. In: 40th A1AA Aerospace Sciences Meeting \& Exhibit. Reno, NV, US; 2002.

11.Owis F.M., Nayfeh A.H.: Numerical simulation of super- and partially-cavitating flows over an axisymmetric projectile. In: 39th AIAA Aerospace Sciences Meeting \& Exhibit. Reno, NV, US; 2001.

12.Kinzel M.P., Lindau J.W., Kunz R.F.: Free-surface proximity effects in developed and super-cavitation. In: DoD HPCMP Users Group Conference, 2008.

13.Seif M.S., Asnaghi A., Jahanbakhsh E.: Drag force on a flat plate in cavitating flows. Polish Maritime Research, 2009.

14.Kuklinski R., Fredette A., Henoch C., Castano J.: Experimental Studies in the Control of Cavitating Bodies. In: Guidance, Navigation, and Control Conference and Exhibit. Keystone, Colorado, USA: AIAA; 2006.

15.Choi J.H., Penmetsa R.C., Grandhi R.V.: Shape Optimization of the Cavitator for a Supercavitating Torpedo. Struct Multidisc Optim, 2005.

16.Shafaghat R., Hosseinalipour S.M.: Shape Optimization of TwoDimensional Cavitators in Supercavitating Flows, Using NSGA II Algorithm. Appl. Ocean Res., 2008.

17.Lin M., Hu F., Zhang W.: Optimal Design of Conical Cavitator of Supercavitating Vehicles. Journal of National University of Defense Technology, 2010.

18.Savchenko Y.N.: Supercavitating object propulsion. In: RTO/ NATO Lecture Series 005 Supercavitating Flows. France; 2002.

19.Miller T.F., Herr J.D.: Green Rocket Propulsion by Reaction of Al and Mg Powders and Water. In: 40th AIAA/ASME/ SAE/ASEE Joint Propulsion Conference and Exhibit. Fort Lauderdale, Florida; 2004.

\section{CONTACT WITH THE AUTHORS}

Zhenyu Jiang, Associate Research Fellow, Min Xiang, Lecturer, Mingdong Lin*), Ph.D., Weihua Zhang, Professor, Shuai Zhang, M.Sc.,

Team 6, College of Aerospace Science and Technology National University of Defense Technology Changsha, P.R. China, 410073

*) Corresponding author. e-mail: lmd231@yahoo.com.cn 